\title{
DOS DOGMAS DEL FEMINISMO
}

\author{
CARMEN GONZÁlEZ MARÍN \\ Grupo Korè. Estudios de Género/UC3M
}

Recibido: $24 / 02 / 2010$

Aceptado: 12/03/2010

\section{Resumen}

En este trabajo me propongo analizar dos de las creencias que, dogmáticamente, determinan nuestras visiones del mundo desde perspectivas feministas. El primer dogma es que la mujer es la otra del varón, es decir, que la alteridad es responsable de la subordinación femenina. El segundo dogma afirma que la alteridad exige superarla o vindicarla. Consideradas las únicas maneras de resolver el problema de las mujeres, esta pareja de alternativas conducen a un callejón sin salida, que explicaría el giro post-feminista.

Palabras clave: alteridad, identidad, postfeminismo, Agacinski

\begin{abstract}
In this paper, I will analyze two dogmatic feminist presuppositions. First, that women are the paradigmatic other, which means, that otherness is responsible for the exclusion or subordination of women. Second, that we are obliged to overcome or vindicate otherness. Taken as the only way out, these two possibilities lead to an impasse, that would explain the post-feminist turn.
\end{abstract}

Keywords: otherness, identity, postfeminism, Agacinski 



\section{El post-feminismo como fatiga}

Desde que en los 90 el término «postfeminismo» se puso de moda y comenzó a ser extensivamente utilizado, especialmente en los media, pudiera pensarse, se plantea un problema nuevo para los feminismos, o, incluso, en el peor de los casos, se diría que hace su aparición en escena un serio competidor. Es cierto que no hay gran acuerdo respecto al sentido del término mismo, y sobre todo acerca de su valor, pero también es cierto que se ha convertido en un término al menos funcional, lo suficientemente funcional como para obligarnos a tomarlo en consideración y preguntarnos acerca de ese sentido y ese valor que no están claros. Sea el postfeminismo una suerte de regresión a una forma de pre-feminismo, o sea una superación de los feminismos, el hecho es que obviamente señala en una dirección poco discutible de entrada, si queremos pensar honestamente: pasamos página respecto a lo que denominamos genéricamente "feminismo".

Si hacemos un breve recorrido a través de los usos del término "postfeminista», como el que realiza por ejemplo Sarah Gamble en su trabajo «Postfeminism $»^{1}$, si nos preocupamos de sus ejemplificaciones en libros bien conocidos, seguramente resultará muy tentador quedarse con la traducción de postfeminismo como regresión ${ }^{2}$. Por otra parte, si acudimos a otras autoras, como por ejemplo Sylviane Agacinsky, cuyo Políticas de Sexos se concibe como un texto postfeminista también, no es tan claro desde luego que la noción de regresión, o la voluntad, explicita o simplemente reprimida de regresión, estén implícitas en su trabajo y en sus propuestas de un universalismo con sujeto doble. Pero, en cualquier caso, lo cierto es que una vez aprendido el término y usado aquí y allá, pasamos página de algún modo.

Probablemente, no haya motivos suficientes para pasar página, ni mucho menos para justificar esa actitud, pero si hay quizá ciertas razones que

1. Gamble, Sarah (ed.). Routledge Companion to Feminism and Postfeminism. New York, Routledge, 2006.

2. Pensamos en el caso de Nigella Lawson, como lo recoge el artículo de Joanne Hollows «Feeling Like a Domestic Goddess. Postfeminism and Cooking», European Journal of Cultural Studies, vol 6(2) (2005), pp. 179-202. 
potencialmente explican ese aparente rechazo que percibimos en ocasiones ante la pervivencia de los feminismos. Estas razones podrían condensarse en una percepción sesgada de los feminismos, y una cierta respuesta emocional confusa ante los mismos o sus consecuencias. Pero igualmente hay ciertas creencias que son propiamente feministas, de algún modo, y que también quizá podrían o merecerían ser revisadas. Esa percepción sesgada a que me refería se aprecia en la versión de los feminismos como algo caducado, por exitoso o por fracasado. La respuesta emocional confusa es meramente el efecto de una percepción errada del éxito de los feminismos, que habrían dado lugar a lo que se puede denominar, sin ánimo de hacer propaganda a un infausto texto de no hace mucho, un revanchismo de género. Naturalmente una y otra cosa se enmarañan lo suficiente como para hacer de los feminismos un objeto relativamente detestable, desde el punto de vista tanto de quienes se consideran suficientemente bien inscritas en la vida común y digna, como de quienes se consideran de algún modo damnificadas, agredidas por ciertas políticas feministas, o simplemente por la experiencia de una fatal pérdida en la calidad de vida gracias a los avances feministas. El término «revanchismo» ciertamente es odioso, pero puede rescatar parte de las resistencias o de las expresiones de resistencia tan al uso (sorprendente) entre jóvenes mujeres, del tipo del vulgarizado «el feminismo es lo contrario del machismo», naĩveté que más de mil veces escuchada es el mejor exponente de esa resistencia

En cierto modo, los feminismos han envejecido y no solo desde el punto de vista social, como movimientos potencialmente revolucionarios con ansias de totalidad, sino conceptualmente. Parece que todo cuanto nos ha quedado, aparte naturalmente de las sustanciales modificaciones en las vidas de muchas mujeres, y en la vida tout court, es un acartonado modo de entender la historia de las mujeres, y sus presentes y aspiraciones. Trivialmente, que algo ha terminado comienza a manifestarse cuando se encuentra una denominación para otra cosa que contiene su nombre tras el prefijo post. Como no se ha convertido ciertamente en extraño oír hablar de post-feminismo, en buen juicio, se podría pensar que realmente aquél, el feminismo, está más próximo a la arqueología que a la vida, incluso a la que pomposamente podría denominarse la vida del espíritu. Sin necesidad de dejarse llevar por algo como la añoranza, no es difícil constatar que entre muchas mujeres jóvenes la propia denominación «feminista» parece chirriar, presumiblemente no por los mismos motivos que chirriaba entre algunas mujeres adultas hace decenios. Es interesante preguntarse, desde luego, qué está pasando, cuál es la recepción real del feminismo, al menos del feminismo académico, como para que las hijas de madres potencialmente feministas ya no deseen ser reconocidas bajo 
esa rúbrica - aparentemente sin renunciar a las exigencias de las feministas más clásicas.

\section{Dogmas}

Remedando el título del famoso trabajo de W. V. O. Quine ${ }^{3}$, en «Dos dogmas del feminismo» me propongo analizar dos de las creencias que, indiscutidas, es decir dogmáticamente, determinan nuestras visiones del mundo desde perspectivas feministas, y no solo feministas incidentalmente. El primer dogma afirma que si las mujeres han sido subordinadas, excluidas o confinadas es porque son la otra del varón, es decir, que es la percepción errónea de la alteridad, o su mera existencia construida, lo que hace de las mujeres potencialmente subordinables. El segundo dogma afirma que solo hay dos procedimientos para resolver la situación en que nos coloca la alteridad, bien o mal interpretada: superarla o vindicarla - superar o reinscribir el problema de la alteridad. Se da por hecho, pues, que la exclusión y la subordinación de las mujeres tienen su fundamento en la interpretación de aquéllas como lo otro del varón, y a continuación se asienta el supuesto de que romper con las políticas de exclusión y de subordinación de las mujeres exige necesariamente decidirse por una de las dos alternativas bien conocidas: o bien borrar las diferencias que originan el estado indeseable al que se ven abocadas las mujeres, o bien convertir nuestra interpretación de las mujeres y, en consecuencia, las «políticas de sexos», en específicamente sensibles a esas diferencias que definen a la mujer como lo «otro» del varón. Los dos dogmas a que me refiero tienen que ver con los dos tipos dominantes de feminismo tal como académicamente al menos -y también popularmente quizá- los percibimos hoy. No sorprende seguramente tras esto que cualquier otro modo de enfrentarse al caso o a los casos de las mujeres terminen por denominarse postfeminismo.

Los dos modos dominantes del feminismo, que tradicionalmente hemos denominado igualitarista y diferencialista, respectivamente, parecen haber mostrado su ineficacia como teorías completas y como propuestas suficientes para alcanzar el propósito aparentemente buscado, esto es la emancipación total de las mujeres. Es cierto que la expresión «emancipación de las mujeres» admitiría múltiples lecturas, y ésa es la razón de la ineficacia de cualquier potencial teoría o batería de propuestas que se nos ocurriera hacer en cualquier caso. Desde cierto punto de vista, emancipar a las mujeres queda traducido más fácilmente desde una perspectiva igualitarista, puesto que contábamos

3. QUinE, Willard Van Orman. «Dos dogmas del empirismo». En Quine, Willard Van Orman, Desde un punto de vista lógico. Barcelona, Orbis, 1984, pp. 49-82.

Feminismo/s 15, junio 2010, pp. 55-74 
con un modelo de sujeto emancipado. El varón blanco de cierta solvencia económica y cierto nivel de poder se podría considerar el tipo de sujeto libre y autónomo, y por ello emancipado por antonomasia. De modo que aproximarse lo más posible a ese modelo podría muy bien constituirse en el objetivo de todo proceso emancipatorio. El primero de los modelos dogmáticos del feminismo se genera, pues, a partir de esta percepción de un modelo de sujeto. Sin embargo, eso no significa lo que, ingenuamente, se podría traducir como toda mujer emancipada es un varón, sino precisamente algo que esta por debajo de esa vulgaridad: toda mujer debe ser emancipada siguiendo un único patrón. Pero la necesidad de emancipación no era solamente una creencia y una obstinación de las igualitaristas, sino de los feminismos de la diferencia igualmente: La única discrepancia es que, en este segundo caso, se trata precisamente tanto de huir del modelo varonil, como del modelo femenino impuesto por el patriarcado, que falsea la realidad de las mujeres. Se trata pues de una creencia indiscutida cuya principal característica es su carácter unilateral que afecta a todo modelo de feminismo, aunque no se manifieste en políticas semejantes en todos los casos. La falta de univocidad no modifica en realidad el propósito último. Es precisamente ese carácter dogmático lo que genera contraejemplos a las tesis feministas y desde luego, me temo, ese tipo de extraña resistencia que percibimos de manera sorprendente entre ciertas mujeres, y especialmente entre ciertas mujeres jóvenes.

La noción de emancipación, sin embargo, puede ser en algún sentido problemática. Desde un punto de vista que podría considerarse conservador, es fácil sostener que la emancipación igualitaria exige renuncias. Y, por otra parte, la liberación del impacto que la falsa imagen que arroja el patriarcado sobre las mujeres, desde el punto de vista de quienes postulan la vindicación de la diferencia, también exige otro tipo de renuncia; esta vez parece necesario renunciar a la posibilidad misma de alejarse «de la naturaleza». Se diría que mantener el dogma a toda costa exige, pues, ser ciega a las diferencias reales entre situaciones de mujeres, y a las propias exigencias, y especialmente, algo muy relevante y tantas veces resaltado por ciertas no feministas, olvidarse de la posibilidad de elección de formas de vida. Pero no es extraño que el argumento de la elección se plantee como el dilema entre ser realmente una mujer emancipada, o seguir la propia voluntad o interés o lo que pide el corazón. Desde este punto de vista, la voluntad férrea de salir de los goznes de la vida tradicional se podría percibir por parte de ciertas mujeres incluso como manifestación de un exceso, de una suerte de hybris difícil de tolerar por su propio carácter intolerante. Para muchas otras mujeres, en cambio, el exceso radica en la exacerbación de lo femenino y de sus consecuencias, entre otras, 
la victimización, que podría percibirse como consecuencia de la vindicación de la diferencia. Lo cierto, a pesar de todo, es que dejarse llevar por el cansancio o el exceso de optimismo respecto a la situación de las mujeres también supone un riesgo importante. Por ello sigue siendo necesario pensar, y actuar en consecuencia.

\section{Alteridad y deficiencia}

Pasemos el primero de los dogmas. La primera cuestión que llama la atención es que, a pesar de que al parecer creemos efectivamente que la alteridad femenina es la responsable de la lectura de la diferencia especifica como deficiencia, es precisamente esa lectura, realizada oblicuamente, la que nos ayuda a deconstruir la propia noción de alteridad. Es cierto que la imagen misógina de las mujeres hace de ellas un ser caracterizado por un conjunto de propiedades específicas que las hacen ser lo que son, pero esas propiedades, como es sabido, suelen ser la cara negativa de las buenas propiedades de los varones; o sencillamente descubrimos que las propiedades positivas adscritas a los varones brillan por su ausencia en las mujeres. En una sencilla serie de las oposiciones tan gratas a la filosofía, el varón está del lado de la virtud, de la razón, de la acción, mientras que la mujer queda señalada por sus carencias. $\mathrm{O}$ al menos esto se sigue de muchas de las ideas sobre las mujeres que han prevalecido en nuestra tradición. Sin embargo, en realidad, quizá las cosas son de otro modo: Cuando se dan las mismas propiedades en varones y mujeres aquéllas adquieren otro valor distinto en uno u otro caso. Muchos ejemplos ilustran este movimiento (es decir contribuyen a crear la impresión de que las mujeres carecen de algo que, en realidad poseen, al convertirlo en negativo, cuando era positivo en los varones). Veamos uno muy clásico: en Corbacho, texto misógino sin fisuras, el Arcipreste de Talavera nos pone ante los ojos una interesante ilustración de ese movimiento. Su capítulo XVII lleva por título «Cómo los letrados pierden el saber por amar», y en él pasa revista a varios casos notables en los cuales la relación con las mujeres ha hecho perder sus virtudes, incluidas las intelectuales. Antes de entrar en materia, el escritor advierte de algo llamativo (citaré literalmente, porque es sabroso): «Antes te digo que los que más científicos son, después que en tal uso se envolviesen - en el amor y la lujuria - menos se saben desenvolver de ello que los simples ignorantes...» Y luego: «¿Quien oyó decir que Aristóteles, uno de los letrados del mundo e sabido, sostener ponerse freno en la boca e silla en el cuerpo, cinchado como bestia, e ella, la su coamante, de suso cabalgando, dándole con unas correas en las ancas? ¿Quién no debe renegar de amor sabiendo que loco amor fizo de un tan gran sabio sobre cuantos fueron sabios, fazer del bestia enfrenada, 
andando a cuatro pies como bestia, una simple mujer? $»^{4}$ El docto letrado no era otro que Aristóteles, cuya vodevilesca historia con la esposa de Alejandro tanto ha dado de sí en la iconografía.

Un ciudadano es en Aristóteles un hombre en cuya vida activa se incrementa y resplandece la virtud. Como es sabido, Aristóteles elabora un ejemplar argumento en su Política para justificar la exclusión de las mujeres de la polis, y por tanto del tipo de vida que caracteriza a un ciudadano virtuoso ${ }^{5}$. La fundamentación del argumento, problemático por lo demás, es la jerarquía que la naturaleza manifiesta entre los seres vivos y particularmente entre varones y mujeres. ¿Significa esto que la mujer jamás podría ostentar alguna forma de jerarquía sobre al varón? Los relatos desde el Lai de Aristóteles al Corbacho, las estatuillas, o los grabados, nos presentan una misma escena que contradice tal presuposición cómicamente. Contemplamos a un varón a cuatro patas, y sobre él cabalga una dama que lo tiene embridado y, látigo en mano, exhibe la actitud propia de quien domina en una relación sadomasoquista. Lo interesante, y fuera de todo ánimo erudito, es que la imagen de este Aristóteles es un varón en una actitud indecorosa. Pero lo indecoroso de la actitud no es probablemente sino el ofrecer el aspecto de ser dominado por una mujer. Si es indecorosa la imagen es específicamente porque el varón se dejó dominar «por una simple mujer.» Lo que hace el loco amor desordenado y peligroso para todos -subrayo el género masculino- es que contamina, contagia de lo negativo de la mujer. Así el varón se convierte, en nuestro vocabulario, en mujeriego -contaminado- mientras que no existe un nombre para la mujer de prolija vida sexual que denote una simétrica contaminación por el varón, sino que su denominación es en este caso intrínsecamente femenina, y sirve, de paso, para explicar la lacra moral del mujeriego.

En el marco de la teoría aristotélica de la jerarquía entre los sexos, se explica el sarcasmo de la imagen que no obstante desempeña como vemos en la «lectura» del caso por parte del Arcipreste de Talavera un papel ejemplificador, no como muestra de la maldad del varón sino de la de la mujer que a todo alcanza, si no se guardan las distancias debidas, si aquél no se protege convenientemente. No es aventurado afirmar que el propio Aristóteles se

4. Martínez de Toledo, Alfonso. Arcipreste de Talavera o Corbacho. Madrid, Castalia, 1970 , pp. 76 y 77.

5. Vid. mi «Parole et justice», en CHristensen, Birgit (ed). Wissen, MAcht, Geschlecht / Knowledge, Power, Gender. Philosophie Und Die Zukunft Der "Condition Féminine» / Philospphy and the Future of the "Condition Féminine». Zurich, Chronos, 2002; o «La ansiedad de la diferencia» en GONZÁlez MARín, Carmen y Huguet SANTOS, Montserrat. Género y espacio público. Nueve ensayos. Madrid, Dykinson, 2008. 
habría sentido embarazado, y no sólo por la publicidad de sus vicios privados, o de su debilidad, sino más bien porque la posibilidad misma de tal debilidad pone en tela de juicio la solidez de sus argumentos, y de lo que han justificado en nuestra tradición, la subordinación de las mujeres debida a su deficiencia. Lo que el Aristóteles sometido por la joven nos enseña es que la naturaleza que crea la jerarquía también la deconstruye; que, en resumidas cuentas, no es la deficiencia natural de las mujeres lo que las hace diferentes y subordinables, sino que es precisamente la posibilidad misma de su superioridad lo que se esconde tras la maniobra de su exclusión. Y no deja de ser interesante que la superioridad de las mujeres se localice en una imagen sexual -es una nueva ironía, porque, de nuevo en términos de un argumento «aristotélico», es la especialización de las mujeres como objeto sexual y reproductor lo que las convierte en instrumentos del varón y por ello, mediante un sencillo silogismo, en inferiores a él- puesto que el instrumento es como una parte de quien lo utiliza y la parte es inferior al todo, el instrumento es inferior al (todo) que lo utiliza.

Podríamos aventurarnos a realizar grandes saltos en la historia con resultados sorprendentemente semejantes. Cuando la mujer representa el sexo es para mal, pero cuando la sexualidad pasa a significar algo positivo porque sustenta la acción, o, en términos existencialistas, es sustrato de la trascendencia, entonces las mujeres son deficientes sexualmente. Freud es el mejor maestro para enseñarnos cómo la sexualidad femenina consiste en la ausencia de la misma, y cómo esto se constituye en términos normativos. Sus conferencias «La feminidad»y «Sobre la sexualidad femenina ${ }^{6}$, como es sabido, reinscriben la sexualidad femenina en el espacio normativo de la renuncia. Pero lo curioso e interesante es el camino que se ve obligado a recorrer Freud para justificar la exclusión de las mujeres de la sexualidad, cuando inicialmente había afirmado un cierto exceso de libido en las niñas, que comienzan por ser «bisexuales», es decir poseedoras de una suerte de duplicación genital, para acabar por carecer del único órgano apto para expresar y realizar la libido. Ese camino pasa por el olvido deliberado de la forma de sexualidad adecuada, y la conversión de su afirmación en vergüenza.

Quizá la moraleja de estos dos ejemplos tan distantes y distintos no sea otra que la ineficacia de la apelación a la alteridad como soporte fundamental de la subordinación o la exclusión o el confinamiento. En realidad, políticamente, no es que la mujer sea la otra, sino justamente lo contrario lo que la

6. FrEUd, Sigmund. «Sobre la sexualidad femenina» (1931). En FreUd, Sigmund, Obras Completas, vol. 21. Buenos Aires, Amorrortu Editores, 1982. Y FreUd, Sigmund. «La feminidad» (1932). En Op. cit., vol. 22. 
hace acreedora de la saña de la misoginia. Y, metafísicamente, no es que sea otra lo que configura su imagen como deficiente, sino que ambos, varón y mujer, son en realidad de la misma naturaleza. De lo contrario sería difícil establecer un criterio del carácter alterado de la una con respecto del otro ${ }^{7}$.

¿Será, acaso, que la noción de alteridad no se utiliza correctamente? Por más que expresiones como la freudiana «el continente oscuro» parezcan remitir al secreto de la otra, no hay tal secreto, sino una impúdica ficción. Las mujeres no son la otra, son lo mismo pero deficiente, alterado, disminuido. Por esa razón se justifica la subordinación. Lo que sucede es que se dan estrategias de construcción del otro (estrategias ficcionales), para evitar el reconocimiento de la radical alteridad de todo y todos, respecto de todo y todos - y respecto de uno mismo seguramente. Así, se puede llegar a construir otros, agrupados en conjuntos definidos por una propiedad o conjunto de propiedades, que pueden sostener una etiqueta, de modo que favorezcan al mismo tiempo una comprensión del nosotros o del yo no problemática. Si tomamos la que no es yo como otro relevante, estamos probablemente admitiendo que no está bajo nuestro control. Sin embargo, el modo en que interpretamos al otro es justamente el contrario: el otro es el resultado de una estrategia de control (el sexo o la raza son buenos ejemplos en esta línea). La alteridad es un procedimiento de control.

El otro es secreto -Jacques Derrida escribió «Autrui est secret, parce qu'il est autre»-, el otro es opaco, es absolutamente no yo. Si reconociéramos realmente la alteridad, no necesitaríamos desde luego de ninguna acción constructiva, porque lo otro, el otro, la otra vienen dados. Si tuviéramos que tratar de elaborar un conato de explicación de la extraña forma de asimilar la alteridad, cuando en el fondo creemos que es el efecto de una construcción interesada, deberíamos tratar de pensar en el modo en que nos vemos a nosotros mismos. Dado que nosotros nos auto-exigimos una transparencia que se corresponda con la auto-percepción privilegiada de la $1^{a}$ persona (al menos en la tradición pre-sicoanalítica, o incluso post-analítica, si y solo si dejamos que el ojo que mira nuestro yo sea el del psicoanalista, que es el suplemento de nuestro propio ojo interno, o el ojo de dios en bata banca), al parecer, exigimos las mismas facilidades en la percepción de otro, de modo que si tal facilidad no se da de suyo, el objeto percibido se convierte en inalcanzable y peligroso sin duda. ¿Quién quería convivir con lo inaccesible, sobre todo si lo inaccesible son todos excepto uno mismo? Quizá este conato de explicación exigiría algo más

7. Véase AgacinSKi, Sylviane. Metafísica de los sexos. Madrid, Akal, 2007. 
de trabajo, pero sin duda, aun como esbozo, permite al menos intuir algunas de las razones de la extraña construcción del otro y de la otra.

No cabe duda de que tendría un enorme interés metafísico realizar una investigación acerca de las razones del creciente interés por las identidades, como la otra cara de la alteridad - no a la inversa, me temo. Parece obvio que la alteridad debe ser pensada como el correspondiente de la identidad, y a raíz del pensamiento de la identidad. Pero algo en el proceso o el tipo de proceso de construcción de la alteridad hace pensar que la fiebre identitaria, o la inflación de las identidades, solo se produce tras la construcción de la noción de alteridad ${ }^{8}$. Precisamente porque aquella es construida parece que se hace necesario aportar este aspecto antimetafísico, en este caso en sentido positivo, a la noción de identidad - por ello se habla de ello en plural, con soltura. En el caso de la identidad hay una ansiedad de control -yo me construyo, y me controlo-, y, al mismo tiempo, una añoranza de la pérdida metafísica seguramente - las tesis en torno a la identidad narrativa van probablemente en esta dirección. Pero ésta es otra historia, una historia nada antimetafísica, de hecho, aunque parezca lo contrario. ¿Qué mejor modo de sostener la autopercepción privilegiada que afirmar que yo soy una figura narrativa, de mi propio relato naturalmente? De modo que, en resumidas cuentas, se diría que la alteridad se descubre como una construcción antimetafísica -por ello, algo no necesariamente predefinido-, y que es ese descubrimiento el punto de arranque de la identidad como construcción antimetafísica (un yo metafísico hace o construye al otro, pero no lo ignora, cree que el otro es dado o simula que el otro es dado.) En general, hemos entendido que el otro era el resultado de la construcción y ello, contamina nuestra propia versión del yo como antimetafísica. Si es ficticia la manera en que se interpreta la alteridad, paralelamente lo será la identidad. Algo que deberíamos tener el cuenta, seguramente a la hora de proseguir el trillado camino de las filosofías y políticas identitarias.

\section{Sujetos y etiquetas: cómo acabar de una vez por todas con la identidad}

Las batallas del feminismo de todo tipo se han jugado o se juegan todavía en la arena de la oposición identidad/alteridad. O la mujer es otra y sin embargo no se comprende, o bien es otra como resultado de la construcción más o menos malevolente del patriarcado. Algo se pierde sin embargo en las dos posiciones. Acabamos de ver que la determinación de la mujer como otra, lo otro del varón, exige algo más que la percepción de la diferencia. Pero sobre todo que es

8. En realidad, la visión nietzscheana de la estrategia en que construimos la noción del bueno, en la Genealogía de la moral, nos enseña ese movimiento.

Feminismo/s 15, junio 2010, pp. 55-74 
precisamente esa alteridad lo que se reprime en esencia, con vistas a mantener a raya la potencial disparidad y rebelión ante la jerarquía. La maniobra que hace de la mujer otra es complicada, y sólo tentativamente la describiríamos como un camino doble de ida y vuelta, que consiste en convertir las propiedades que pudiera compartir con el varón en negativas, y, de ese modo, hacer de la mujer un sujeto marcado como deficiente, pero sin olvidar que el carácter negativo de las citadas propiedades se debía a que eran aplicadas a la mujer.

La alteridad no es una categoría cuya inmediatez o carácter indiscutible nos permita asumir, sin más, la necesidad de establecer la doble estrategia que el feminismo ha dado por sentado era necesaria: o bien luchar por la igualdad, es decir por la borradura de aquello que sostienen la visión de las mujeres como lo otro del varón, o bien sostener lo específico de esa alteridad, como aquello constitutivo de lo femenino, y, por ello, lo que ha de ser salvado y reivindicado. En ambos casos, el feminismo no ha podido salir de las fronteras de una u otra forma de esencialismo, y acaso por ello la gran revolución social protagonizada por las mujeres no ha terminado todavía, y presenta flancos desprotegidos políticamente, y conceptualmente paradójicos.

Es sensata y acertada la crítica tradicional al feminismo de la igualdad: efectivamente se atiene a la creencia en la existencia de un solo tipo de sujeto valioso y por ello se queda paradójicamente en una proclama patriarcal. Y la otra manera de plantear el feminismo tradicionalmente, la diferencialista, tampoco deja de caer en la trampa de otro modo de esencialismo: si la igualdad supone que no es pensable sino un tipo de sujeto, la diferencia establece dos tipos de sujetos igualmente inamovibles. El camino es de la postulación de la deficiencia al restablecimiento de la misma en forma de diferencia, pero el carácter problemático de la identidad de las mujeres y de las estrategias necesarias para lograr formas de vida mejores y más justas se mantiene inalterable.

Sin necesidad de prolijos análisis, podemos asumir que en cualquiera de los dos casos el referente es o soterradamente único (y en este caso el feminismo es una manera de crear barreras de protección a la manera de la Ciudad de las damas), o, por el contrario, se están postulando dos modos de ser sujeto que conservan sin embargo, contra todo lo deseable, una marca normativa, y a duras penas hemos avanzado sobre la tensión entre los planteamientos de República Libro V y Política Libro I. Las paradojas a que me refería más arriba se deben precisamente al mantenimiento del referente único, al tiempo que se ha asumido universalmente la autonomía femenina, que hace que el sujeto neutro con el que soñaban las feministas se vea teñido de excesos de feminidad. Pero a la vez la reivindicación de esa feminidad se plantee desde 
la autonomía modelada sobre un sujeto neutro - o acaso varonil. La segunda posibilidad nos hace pensar en el carácter separatista, y por ello irreal, que puede ostentar el diferencialismo. En resumidas cuentas, parece como si el feminismo se hubiera preguntado demasiadas veces si hombre y mujeres son iguales o diferentes hasta llegar a creer que igualdad y diferencia nombran dos tipos de seres humanos ${ }^{9}$. Y que lo que determina a las mujeres es su carácter de otro de los varones, y que la alteridad es precisamente aquello que hay que deconstruir, o reconstruir en su caso, desde el activismo.

El segundo dogma nos obliga, pues, a plantearnos la alternativa entre dos formulas del feminismo tradicionales - no es necesario recalcar que es preciso plantearse si no son los dos dogmas, y no solo los medios de comunicación, los responsables de la cesión de terreno por parte de los feminismos. Pero en realidad, ¿cuál es el problema? Veamos la cuestión inscrita en las dos fórmulas al uso. Si la solución al problema que plantea la alteridad es superarla, tal como pretende el feminismo de corte igualitarista, ¿qué estamos diciendo? Normalmente estaríamos diciendo que la alteridad es el resultado de una construcción -lo cual es de algún modo correcto- y que por ese motivo es superable. Hay solamente que romper con el objeto o constructo cultural. Roto el constructo cultural, descubrimos que ¿somos iguales? Pero aquí nace otro nuevo problema, a saber: si somos iguales, ¿qué puede justificar el viejo argumento de la elección (de formas de vida)?

La capacidad de elección entre formas de vida activas y no activas, o productivas y no productivas, es sin duda el gran bache en el igualitarismo. La tensión que parece imponer el igualitarismo es pues la que se da entre los objetivos deseados y la renuncia implícita o no a la feminidad o a alguna de sus manifestaciones - o sea, incorporación frente a renuncia. Si optamos, por el contrario, por la vindicación de una alteridad esencial observaremos que la tensión que se plantea ya no es entre la incorporación y la renuncia, sino entre la realidad esencial y la percepción viciada (la alteridad es una ficción porque es, de nuevo, una construcción interesada, que oculta la verdadera forma de ser otra). De modo que la tarea consiste en destruir la falsificada feminidad perniciosa para las mujeres - no basada en su experiencia y su autopercepción. No se trata de incorporarse a nada, sino por el contrario de salir definitivamente de la horma de la feminidad patriarcal, y ser verdaderamente femeninas. El potencial revolucionario de este modo de pensar es mayor, sin duda, que el que presentaba el feminismo de la igualdad. Pero la cuestión

9. Es aproximadamente lo que sostiene Monique Wittig con gran finura en «El pensamiento heterosexual». Véase WitTig, Monique. El pensamiento heterosexual y otros ensayos. Madrid, Egales, 2006. 
que acude inmediatamente a la mente es $i$ Nos conformamos con un mundo de mujeres, o deseamos los «privilegios» del varón? - ¿un trato igualitarista? Una y otra forma de entender la salida de la alteridad reposan en una falacia - que se asienta en el primer dogma: «las mujeres son otras como constructo o como naturaleza». Dejar de ser esa construcción ficticia exige olvidarse del género como constructo cultural; y dejarse ser naturalmente la otra que se es exige, por su parte, no jugar el juego dominante - des-adaptarse, en suma. En el fondo, en los dos modelos está en disputa algo semejante, sólo que se estima de modos diferentes: el trato condicionado por la ontología. Las tensiones no resueltas podrían explicar el post-feminismo como cansancio.

El feminismo igualitarista nos enseña que no podemos lograr una emancipación femenina en una estructura patriarcal, pero no ataca propiamente a la estructura misma, sino al modo en que nos afecta, es decir, al género. Sin embargo, como es bastante obvio, por ejemplo en Simone de Beauvoir, la liberación del género no supone la liberación de la biología, que sigue siendo un handicap para las mujeres, o una trampa para sus objetivos emancipadores. Y ésta es la razón por la que ciertas pensadoras, como Monique Wittig descubren muy pronto que el problema no es interno, no tenemos el enemigo dentro como afirmaba de Beauvoir, sino que el enemigo está precisamente en la estructura patriarcal misma - el pensamiento heterosexual ${ }^{10}$. Pero, por su parte, la diferencia asumida con toda su carga destructora del cliché patriarcal y del universo varonil condena a las mujeres a no ser nada, o a inventar un universo paralelo, lo cual parece retrotraerlas al momento pre-feminista, o a un compromiso revolucionario, que quizá se plantea objetivos imposibles.

Está fuera de duda, estimo, el valor y la eficacia de los dos modelos en ciertos aspectos de la vida de las sociedades, y de la vida de las mujeres en particular. Pero seguramente también estará fuera de duda su agotamiento conceptual. Si en el caso del feminismo igualitarista se puede poner en tela de juicio el optimismo acerca del sistema al que las mujeres deben integrarse, en el diferencialista cabe pensar en el fracaso de la colectivización de las mujeres. Parole de femme ${ }^{11}$ presupone quizá ingenuamente que todas las mujeres se habían de reconocer en la femme - algo viejo y lastrado de esencialismos poco amistosos. Fuera del problema genérico que tal cosa plantea, (¿Dónde están los sujetos colectivos?), el hecho es que el modo en que se define a la mujer puede conducir a rechazos tan fuertes como el de ciertos aspectos biológicos por parte del feminismo igualitarista. Por no mencionar lo que se

10. Sin duda, «No se nace mujer», o «La categoría del sexo», así como «El pensamiento heterosexual» son textos capitales.

11. LeClerC, Annie. Palabra de mujer. Buenos Aires, Megápolis, 1977.

Feminismo/s 15, junio 2010, pp. 55-74 
podría tomar como excesos de la diferencia, tal como los denunciaba Badinter en Fause Route ${ }^{12}$, por ejemplo. De modo que, en realidad, parecería que uno y otro modo de expresar o de traducir el segundo dogma nos conduce a un callejón sin salida, al menos conceptualmente. No es así extraño que algunos provocadores adviertan de la necesidad de salir de los goznes de la discusión, y que lo hagan no solo a instancias del imperativo de la fatiga, sino esencialmente como un procedimiento de escapar a lo que ya parece clausurado, cuando algunos de los problemas de las mujeres no se han resuelto y se manifiestan en formas intolerables, incluso la violencia física y el asesinato.

\section{Una post-feminista metafísica}

Sin dejar de autodenominarse postfeminista, Sylviane Agacinski concibe su reflexión no como una manera de evadirse o de renegar de los feminismos, sino como la necesaria evolución de los mismos. Con la acusación de abstracción y separatismo respectivamente, para los igualitarismos y los diferencialismos, Agacinski se sitúa fuera de esa tensión y trata de ajustar un programa político universalista y paritario a una necesidad - subrayo, en todos los sentidos del término «necesidad»-metafísico-biológica. Su descubrimiento de la relevancia política del doble origen y al tiempo su valor filosófico.

En Políticas de $\operatorname{Sexos}^{13}$, señala como diagnóstico del estado del feminismo un cierto agotamiento y en cierta manera la pervivencia de viejos esquemas que dificultan las trasformaciones sociales y conceptuales que son aún necesarias, como si tanto las versiones misóginas como las feministas se hubieran efectivamente construido sobre un mismo supuesto metafísico. Si bien la postulación del mismo, por su parte puede resultar relativamente complejo, parece también plausible. Señala Agacinski la necesidad de reconsiderar el doble origen biológico-metafísico, y el error de reproducir por parte del feminismo esa «nostalgia del uno» que ha caracterizado la mayoría de las visiones misóginas también. Efectivamente, podríamos interpretar la imagen femenina como ser deficiente en términos binarios 1/0. A las mujeres corresponde la carencia de las características reseñadas como valiosas (sexualidad, ciudadanía, razón, etc.) Por otra parte, esta versión nos muestra la aversión a la posibilidad de interpretar en mundo como un mundo de dos, dual, y la necesidad de mantenerse en la valoración de lo uno, lo idéntico. En lo que respecta al feminismo, la misma nostalgia del uno es notoria en el caso de la vindicación de la igualdad, al menos en los textos clásicos. Agacinski repasa específicamente la

12. BADINTER, Elisabeth. Por mal camino. Madrid, Alianza, 2004.

13. AgaCinSKI, Sylviane. Políticas de sexos. Madrid, Taurus, 1998.

Feminismo/s 15, junio 2010, pp. 55-74 
«biblia» del feminismo, El segundo sexo, que ciertamente no deja mucho lugar a dudas, pero tampoco las deja seguramente la Vindicación de los derechos de la mujer o los textos de Harriet Taylor Mill. La historia de la filosofía, y nuestra tradición cultural en pleno, acompañan en esta creencia y la soportan con creces. Desde el poema de Parménides a la postulación de un dios uno, y de la reducción de la multiplicidad de las sensaciones a la unidad de la percepción, la ontología, la epistemología, la política o la teología han manifestado el deseo de la unidad que prevalece casi inalterable.

Si Agacinski percibe la negación del dos frente a la valorización del uno es precisamente porque la vindicación del uno niega la alteridad real. Sin embargo, a mi juicio, Agacinski se queda con una posición biologista, que estipula como lo universal necesario un doble origen que va más allá de lo biológico, al tiempo que parece obligarla en algunos momentos a recaer políticamente en ciertas formas de conservadurismo. En cierto sentido, se trata de reivindicar el género femenino de nuevo, sin aceptarlo como degradación cultural de la masculinidad. Perder el miedo, o la vergüenza del género no significa, en su contexto, caer en formulas patriarcales tradicionales, ni olvidar la necesidad de la justicia paritaria. La fórmula «universalismo con sujeto mixto» que resume bien su posición política no es, desde luego, postfeminista en el sentido trivial antes reseñado. Sin embargo, a mi modo de ver cae de nuevo en una suerte de trampa que deberíamos comenzar a desmontar u olvidar. Dicha trampa consiste en asumir que el sujeto en el universalismo, el sujeto de derechos o el sujeto en general debe considerarse con sus atributos. $\mathrm{O}$, en otras palabras, que el trato concedido al sujeto es dependiente de sus atributos. Es verdad que así son las cosas, pero también lo es que se trata de romper con ese modo de hacer, y presuponer que hemos de tener presente la dualidad del sujeto para ser apropiadamente universalista es caer en la trampa de nuevo, una vez más.

Hay, por otra parte, una segunda trampa añadida: el reconocimiento de la dualidad, y su otra cara política, la mixitud es el reconocimiento de clasificar, de un modo supuestamente realista y no sesgado, a mujeres y varones. Pero en esta clasificación naturalista quedan fuera ciertas formas de sexualidad ajenas a la concepción biologista-metafísica del doble origen. En resumidas cuentas, el postfeminismo de Agacinski es un intento de casar las dos modalidades caducadas del feminismo, de guardar lo más valioso y pertinente de cada una de ellas: el universalismo y la diferencia como exigencia de reconocimiento. Se trata de recordar que somos necesariamente diferentes y exigimos necesariamente un trato paritario. 
Sin embargo, probablemente el hecho de no poner en tela de juicio el propio universalismo delata o bien que se reprime la verdadera entidad de la ligadura entre aquél y un tipo de sujeto articular, o que ya se ha producido una ruptura o una deconstrucción de esa ligadura. El universalismo debe ser ciego a las diferencias. El reconocimiento de la dualidad biologico-metafísica supone la exigencia del reconocimiento de ciertos intereses particulares en cierto tipo de sujeto - intereses que no se podrían neutralizar, probablemente, una vez reconocidas las peculiaridades específicas del sujeto en cuestión. Y es esa exigencia la que pone a su vez en tela de juicio el modelo universalista. El universalismo es un modo de mirar que no debe percibir lo que nos separa o lo que nos diferencia, de modo que parece incompatible con la atención a lo particular. De hecho, el modo en que se articula esa tensión, o se conjugan esos dos extremos en los universalismos clásicos, por ejemplo en el paulino, es accediendo a asimilar un mundo dualista, entre cuyos dos niveles diferentes no se produce intersección alguna - en la vida mortal somos diferentes, en el mundo celestial o ante Dios somos todos iguales ${ }^{14}$. ¿Es eso lo que queremos? Y en segundo lugar esa sensibilidad hacia lo particular, ¿solo tiene dos posibles objetos, predefinidos por el doble origen?

\section{Coda: la ansiedad clasificatoria}

Si hay algo que caracteriza tanto al feminismo de la igualdad como al de la diferencia es su ansiedad clasificatoria se diría. En el primer caso, hay un grupo y un residuo deficiente - que se reinscribe como otro. En el segundo caso, hay dos grupos claramente diferenciados sin intersección entre ambos. Desbaratar la clasificación en el primer modelo no supone terminar con la vocación de clasificar, sino meramente integrar el residuo o excedente en el grupo dominante. Paralelamente, en el segundo caso no existe voluntad de modificar la clasificación sino su evaluación, la manera en que se experimenta, tal vez.

Clasificar es un procedimiento de control muy sencillo - y de control biopolítico, desde luego. La respuesta a la rigidez clasificatoria ha sido la prevalente vocación de vindicación de lo inclasificable, naturalmente. Contra la rigidez, sobreabundancia de identidades sexuales, de preferencias, de peculiaridades que se suman para desclasificar y en el fondo para reclasificar, de nuevo, individuos en nuevas categorías. $\mathrm{O}$, en la euforia anti-re-clasificatoria, asumir simplemente la carga biopolítica de cualquier forma o formula de vida o de respuesta o de resistencia, y como parece ser el caso que presenta

14. BOYARIN, Daniel. «Paul and the Genealogy of Gender», Representations, 41 (Winter 1993), 1-33.

Feminismo/s 15, junio 2010, pp. 55-74 
Testo yonqui de Beatriz Preciado ${ }^{15}$ tratar de hacerse inclasificable, mediante la profusión de potenciales clasificaciones más o menos abortadas ${ }^{16}$. Los procesos que van de la acción colectiva al individualismo y vuelta del revés son curiosos. Si llevamos a cabo un intento de narración que dé cuenta de la evolución de los feminismos y de los denominados postfeminismos, o de lo que sencillamente denominaríamos los intentos de emancipación, veríamos que en este último extremo resulta difícil hurtarse al afán de control, autocontrol y control del otro. Es obvio que precisamos de definiciones, para asegurarnos tales controles, y esas definiciones, en suma, acabarán por desvirtuar el propio afán individualizador identitario. Igual o diferente, yo-nosotros o el otro, ésa es la cuestión. Y esa era la cuestión de los feminismos al uso en sus dos vertientes tradicionales. Si no hemos logrado cerrar el problema con su ayuda, probablemente tampoco lo logremos con las políticas identitarias que reinan hoy y recaen en el mismo callejón sin salida. Si somos iguales, ¿qué identidad hemos de buscar/mostrar?; si lo relevante es la diferencia identitaria ¿qué igualitarismo es posible? ¿Acaso no hemos entendido realmente, profundamente, el mensaje igualitarista? Igual es igual en responsabilidades -naturalmente salvando el escollo que describe Beauvoir en la vida de las mujeres: su elección vital tiene (¿todavía?) algo de trágica: o se es mujer tradicional o se es mujer emancipada, pero hay que renunciar a algo en cualquiera de los dos casos. Esta igualdad de responsabilidades es imposible sin la aceptación y participación de los otros. Es obvio, y hay muestras de ello abundantes, que no se puede de ningún modo intervenir(se) a-críticamente el mundo de las mujeres, como si solo ellas tuvieran que modificar sus vidas.

De los feminismos igualitaristas y diferencialistas hemos aprendido algo desde luego: a saber, que no se ha dejado a las mujeres formar parte de lo común ni tampoco ser lo que realmente son. Pero parece que hemos renunciado a la vez al exceso de abstracción y a la estetización biológico-moral. Sin embargo, parte de la confusión reinante en torno a los feminismos, y a las actitudes razonables, tanto por parte de la sociedad como de las mujeres se deben a una percepción incompleta y acrítica de algunos de los éxitos y propósitos de los feminismos, y, muy particularmente, de la noción de elección. La política de la elección propone una suerte de privilegio femenino. Las mujeres pueden elegir formar parte de la vida común o seguir siendo mujeres tradicionales. Cualquier abogado de la política de la elección afirmará ante nuestras críticas que esa elección no es exclusivamente femenina, desde luego. Sin embargo

15. Preciado, Beatriz. TestoYonqui. Madrid, Espasa Calpe, 2008.

16. GonZÁleZ MARÍN Carmen. «Lo personal es (bio)político», Revista de Libros (en prensa).

Feminismo/s 15, junio 2010, pp. 55-74 
hay algo de extraño en la no poco extendida pretensión de mantener formas de vida- wittgesteinianamente tradicionales - y actitudes que responden a una concepción del empoderamiento incompatible con tales formas de vida. Naturalmente, es un éxito de los feminismos futuros que tal cosa pueda llegar a producirse. Pero es al mismo tiempo un fracaso de cada una de sus versiones y convendría aclararlo en todas ellas.

En realidad todos y todas somos iguales en cierto respecto y diferentes en otro. El problema de las mujeres, o de la agenda del feminismo, no es sin embargo un problema ontológico o metafísico, sino político, y políticamente es irrelevante si somos iguales o diferentes, o en qué nos asemejamos o diferimos. Lo único relevante es ser sujetos de los mismos derechos sin exigir transformaciones sustanciales para serlo. A pesar de que acabo de mencionar la irrelevancia política de nuestra identidad sustancial para ser sujetos de derechos, ello no significa filosóficamente o metafísicamente incluso que sea irrelevante. Muy al contrario, es necesario llevar a cabo un proceso continuo de revisión profunda de nuestro lenguaje, específicamente de nuestro lenguaje político, para que no se reproduzcan los viejos vicios que repercuten, efectivamente, en la aplicación de los predicados correctos a los sujetos -varones y mujeres- y por ello en la acción política. El igualitarismo, que probablemente es la única forma posible de acción política, es efectivamente eso, político, y no ontológico, y eso es tanto como decir que implica obligaciones y reciprocidades.

Si la desclasificación contribuye a ese igualitarismo, y probablemente lo haga, bienvenida sea; pero sin caer en la trampa del postfeminismo que es el empoderamiento ficticio, privado, y sin compromiso público. El postfeminismo abre una trampilla muy peligrosa aunque atractiva: parece permitirnos escapar del tedio del callejón sin salida de la discusión igualdad-diferencia: acogerse a un modo de empoderamiento privado y olvidarse paralelamente del compromiso público que exige como conditio sine qua non la igualdad y la justicia.

\section{Referencias bibliográficas}

AgACINSKI, Sylviane. Metafísica de los sexos. Madrid, Akal, 2007.

Agacinski, Sylviane. Políticas de sexos. Madrid, Taurus, 1998.

BADINTER, Elisabeth. Por mal camino. Madrid, Alianza, 2004.

BOYARIN, Daniel. «Paul and the Genealogy of Gender», Representations, 41 (Winter 1993), 1-33.

Freud, Sigmund. «La feminidad» (1932) en Freud, Sigmund, Obras Completas, vol. 22, Buenos Aires, Amorrortu Editores, 1982.

Feminismo/s 15, junio 2010, pp. 55-74 
FREUD, Sigmund. «Sobre la sexualidad femenina» (1931). En FrEUD, Sigmund, Op. cit.,, vol. 21, Buenos Aires, Amorrortu Editores, 1982.

Gamble, Sarah (ed.). Routledge Companion to Feminism and Postfeminis. New York, Routledge, 2006.

González Marín, Carmen. «Lo personal es (bio)político», Revista de Libros (en prensa)

GONZÁlEZ MARÍN, Carmen. «La ansiedad de la diferencia». En GONZÁLEZ MARÍN, Carmen y Huguet SAntos, Montserrat, Género y espacio público. Nueve ensayos. Madrid, Dykinson, 2008.

González Marín, Carmen. «Parole et justice». En Christensen, Birgit (ed), Wissen, MAcht, Geschlecht / Knowledge, Power, Gender. Philosophie Und Die Zukunft Der «Condition Féminine» / Philospphy and the Future of the "Condition Féminine». Zurich, Chronos, 2002.

Hollows, Joanne. «Feeling Like a Domestic Goddess. Postfeminism and Cooking». European Journal of Cultural Studies, vol 6(2) (2005), pp. 179-202.

LeClerC, Annie. Palabra de mujer. Buenos Aires, Megápolis, 1977.

MARTínez DE Toledo, Alfonso. Arcipreste de Talavera o Corbacho. Madrid, Castalia, 1970.

Preciado, Beatriz. TestoYonqui. Madrid, Espasa Calpe, 2008.

QuiNE, Willard Van Orman. «Dos dogmas del empirismo». En QuiNE, Willard Van Orman, Desde un punto de vista lógico. Barcelona, Orbis, 1984, pp. 49-82. Wittig, Monique. El pensamiento heterosexual y otros ensayos. Madrid, Egales, 2006. 